\title{
Safe Use and Disposal of Injections: Saudi Health Providers' Perception
}

\author{
Ahmed A. Albarraq \\ Pharmacy Practice Research Unit (PPRU), Department of Clinical Pharmacy, College of Pharmacy, Taif University, Taif, Saudi Arabia. \\ Email: aalbarraq@gmail.com \\ Received November $17^{\text {th }}, 2013$; revised January $1^{\text {st }}, 2014$; accepted January $15^{\text {th }}, 2014$ \\ Copyright (C) 2014 Ahmed A. Albarraq. This is an open access article distributed under the Creative Commons Attribution License, \\ which permits unrestricted use, distribution, and reproduction in any medium, provided the original work is properly cited. In accor- \\ dance of the Creative Commons Attribution License all Copyrights (C) 2014 are reserved for SCIRP and the owner of the intellectual \\ property Ahmed A. Albarraq. All Copyright (C) 2014 are guarded by law and by SCIRP as a guardian.
}

\begin{abstract}
Injection is said to be safe when causing no harm to the recipient, and it does not expose provider to avoidable risk and does not result in any waste that is dangerous for other people. Purpose: The study was carried out to determine the perspectives of the Saudi health care providers on the safe use and disposal of injection. Methods: Prospective cross sectional survey was used, structured interviews were carried out by the use of pretested questionnaire to elicit general opinions on injection practices skills, and disposal processes in different health settings in Taif Area. Results: Females were dominant injection providers $82.3 \%$. About $80 \%$ of providers tend to discard single use injection at once after administration and $84 \%$ tend to safely dispose them. Hygienic measures were well maintained. Increased used pattern of injection was observed $46 \%$. Providers were well satisfied by the measures adopted to curb after using hazards. High rate of injection sticks $74.3 \%$ was observed. Conclusion: Although some measures of safe disposal were maintained by Saudi injections' providers, still some regulation efforts should be done to curb spreading out of infection due to mal use and disposal of injection.
\end{abstract}

\section{KEYWORDS}

\section{Injection Provider; Safe Use; Disposal of Injections; Saudi Arabia}

\section{Introduction}

Injection is one of the most frequently used medical procedures in drug administration [1]. Around 16 billion injections were used to be annually administered in developing countries of a rate of 3.4 per person [2]. Unfortunately, the majority of these injections were unnecessarily administered [3], and reuse of non sterile drug administering tools was a common practice in some countries [4]. WHO attributed the occurrence of more than three hundred thousand of Human Immunodeficiency Virus (HIV) infections, millions Hepatitis B Virus (HBV), Hepatitis C Virus (HCV) and other bacterial infections as a sequence of worldwide vast and unsafe use of injections [3]. Safe use and disposal of injection do neither harm the recipient nor expose provider to any avoidable risk and do not result in dangerous waste for other people, and these are mainly achieved when administered and disposed by qualified and experienced health workers [5].
In general and due to improved screening techniques and superior surveillance measures, the transfusion of transmitted infections has shown a declining pattern in the developed world [6,7]. The infection transmission caused by sexual means continues to decrease, while transmission by injections assumes an increasingly greater role [6]. This was confirmed by the World Health Report 2002 that estimated the unsafe injections accounting for $30 \%$ and $31 \%$ of Hepatitis B and C infections worldwide [8]. The prime objective of this study was to determine the Saudi health workers' opinions on safe use and disposal of injections.

\section{Materials \& Methods}

Cross sectional study was carried out at different health settings in Taif City, Saudi Arabia. The population was a random selection of injections' providers in 15 hospitals and health centers in Taif Area. Pretested survey was 
used. The inclusion criterion for this study was all injections' providers who dully enrolled at the time of the study in the randomly selected health settings in the area.

A proportionate, random sampling method was adopted to generate the sample size of the participants. Register lists of working providers was requested from the Health Directorate in Taif. Sample size was determined using Epi Info software according to the enrolled providers in the selected areas at the time of data collection. Informed consent was obtained from providers before enrollment in the study.

An inclusive questionnaire was used to elicit the general opinions of the injections providers on different assigned variables and to best address the study's objectives. The questionnaire consisted of (6) parts. The first part (5 questions) dealt with healthcare providers' demographic characteristics and basic information on: gender, department, nationality and academic status, etc. The second part (6 questions) dealt with basic information about injection practices. The third part composed of questions about injection disposal processes, (5 questions). The fourth part constituted of three knowledge questions on the common treated diseases by injection, injection medicines and the diseases that resulted from using contaminated needles. The fifth part containing (5 questions) about needle sticks. The last part of questionnaire about providers' judgments on adopted measures of safe use and disposal of injections inside their hospitals. Statistical analysis is performed using the Statistical Software Package SPSS windows version (16). The questionnaire was approved by the Ethical Committee, Pharmacy Practice Research Unit, College of Pharmacy, Taif University. Chi-square and Fisher's exact test were used to measure difference in participants' responses, 0.05 value was used as a cutoff for statistical significance.

\section{Result}

The response rate was (100\%). Females 247 (82.3\%) were dominant injection providers in this study, Saudi locals constituted the majority of them, 127 (42.3\%), followed by Filipino 98(32.6\%) and Indians 59 (19.6\%). Regarding education level, the diploma holders 167 (55.7\%) was dominant, while the university graduates were $128(42.7 \%)$. Most of the responded providers were living in urban areas $248(82.7 \%)$, the majority of them $237(79.0 \%)$ were discard sterile single used injecting devices at once after administration, while 57 (19.7\%) did not do the same.

Regarding the most three factors that of important role to confirm safety in injections use and disposal for health care providers; most of the responded health care workers 264 (88\%) used to wash hands before giving injections to patients, 197 (65.7\%) of them who were used gloves and 222 (74\%) did not recap the needle after use.
An increased rate of injecting pattern was observed: 140 (46.9\%) of providers were used to give 1 - 10 injections per day while $38(12.7 \%)$ of them were used to give more than thirty injections in a working shift. The disposal place is highly affecting the rate of cross infections among injections' providers. The current study revealed a rational pattern of safe injection disposal, 254 (84.7\%) of the interviewed health care providers used to safely dispose injections in special safety boxes, while only 12 $(4.0 \%)$ and $34(11.3 \%)$ of the used injections were respectively dumped on the ground and in litters. Table 1 shows the disposal status of the used injections in the investigated hospitals.

Regarding the regulatory measures to curbing the risks of unsafe use and disposal of injections, most of the providers in the present study 276 (92.0\%) had shown satisfactory responses toward the adopted evaluation measures of preventing after use injections' hazards. In the investigated hospitals 220 (73.3\%) of the interviewed providers had assured the availability of educational posters on injections' use and disposal hazards for both providers and patients. When respondents were asked about the presence of such regulatory measures; 248 (82.7\%) were admitted the availability of continuous evaluation measures in their hospitals. A total of 119 (39.7\%) providers had ascertained that a check procedures were used to be done on a weekly base, while 90 (30.0\%) and 32 (10.7\%) had revealed that these procedures were done on monthly and yearly bases respectively. Out of the responded providers 255(85.0\%) had assured that the health settings who are working in used to present Standard Operating Procedures (SOP) for different activities that securing safe use and disposal of

Table 1. Disposal status of used injections in Taif hospitals.

\begin{tabular}{lcc}
\hline Variables & frequency & Percentage \\
\hline Throw the needle after injection; & 12 & $4,0 \%$ \\
to the ground. & 34 & $11.3 \%$ \\
In litter. & 254 & $84.7 \%$ \\
In special safety boxes & & \\
Place the container after filling; & 132 & $44.0 \%$ \\
Inside the injection room. & 110 & $36.7 \%$ \\
In special room. & 55 & $18.3 \%$ \\
Other places. & 03 & $0.1 \%$ \\
Missed & 98 & $32.7 \%$ \\
Syringes' incineration in the hospitals & 86 & $28.7 \%$ \\
Syringes' incineration out the hospitals & 116 & $38.6 \%$ \\
Providers do not know the incineration place. & & \\
\hline
\end{tabular}


injections. Two hundred thirty eight (79.3\%) of the responded providers had continuous education courses in injection use and disposal management.

The most common diseases treated by injections in Saudi Arabian hospitals as revealed by participants' injections providers, were diabetes 102 (35.9\%),pneumonia 69 (24.3\%)and infectious diseases 45 (15.8\%), while the most injected medicines were antibiotics 138 (46.6\%), insulins 104 (35.1\%) and non steroidal anti-inflammatory agents namely diclofenac 25(8.3\%), Table 2 .

The intravenous route of administration was the most type of injecting route of administration that possibly causes high rate of injuries at the site of administration as revealed by the interviewed providers 144 (48\%), while only $(6.0 \%)$ of providers were agreed on the same injury rate of occurrence among both intravenous and intramascular routes.

Most of the interviewed injections' administrators in the current study 257 (85.7\%) were assured the availability of quite sufficient quantities of disposable injection devices at the time of the investigation visits. While only $37(12.3 \%)$ were admitted deficient quantities of injecting devices at their working settings.

As needle recapping after administration is the one of causative factors of needle stick; 44 (14.7\%) of the inter- viewed providers had admitted a routine recapping, 34 (11.3\%) had sometimes doing the same, while 222 (74.0\%) never recapping needles after administration.

High rate of accidental sticks of used injections was observed as admitted by the fact that 28 (9.3\%) of the injections' administrators had experienced injections' stick/s a week before commencing this study. Most of the injections' providers in the current study 223 (74.3\%) had accidental sticks during their life career, of them, 26 (11.6\%) had less than five sticks and only 5 (2.2\%) had more than five ones.

Hepatitis B is the one of the most infectious diseases that transmitted through accidental sticks of used injections among providers; thus vaccination is a vital preventive measure in curbing the spreading out of HB cross infection. The current study had shown a satisfactory rate of vaccination against Hepatitis B Viral infection (HBVi), 227 (76.4\%) of the investigated providers had vaccinated against (HBVi).

When correlating recapping to providers' education levels; 97 (75.8\%) of the university graduates used not to recap injections after use. While 29 (17.4\%) of the diploma holders used to recap injection after use, no significant difference was observed ( $\mathrm{p}=0.62)$, Table 3 .

Throwing needles after use in special safety boxes by

Table 2. Common diseases treated by injections and most used injection medicines.

\begin{tabular}{|c|c|c|c|}
\hline Disease & Frequency (\%) (percentage) & Medicine & Frequency (\%) \\
\hline Diabetes & 102(35.9) & Antibiotic & $138(46.6)$ \\
\hline Other infections & $45(15.8)$ & Diclofenac & $25(8.3)$ \\
\hline Cesarean section. & 19(6.7) & Heparin & $9(3.0)$ \\
\hline Asthma & 19(6.7) & Hyosine & $7(2.4)$ \\
\hline Hyperthermia & $9(302)$ & Metcloprpamide & $5(1.7)$ \\
\hline Abdominal pain & $7(2.5)$ & paracetamol & $4(1.4)$ \\
\hline ТВ & $6(2.1))$ & hydrocortisone & $4(1.4)$ \\
\hline Total & 284(100) & Total & $296(100.0)$ \\
\hline
\end{tabular}

Table 3. Recapping of used injections by HWs education.

\begin{tabular}{|c|c|c|c|c|c|}
\hline \multirow{2}{*}{ Education } & \multicolumn{3}{|c|}{ Recapping } & \multirow{2}{*}{ Total } & \multirow{2}{*}{$\mathrm{p}$} \\
\hline & Yes & no & some time & & \\
\hline University & $15(11.7 \%)$ & $97(75.8 \%)$ & $16(12.5 \%)$ & 128 & \multirow{4}{*}{0.62} \\
\hline Diploma & $29(17.4 \%)$ & $120(71.9 \%)$ & $18(10.8 \%)$ & 167 & \\
\hline \multirow[t]{2}{*}{ Other } & $0(0 \%)$ & $4(100.0 \%)$ & $0(0 \%)$ & 4 & \\
\hline & $44(14.7 \%)$ & 221(73.9\%) & $34(11.4 \%)$ & 299(100.0\%) & \\
\hline
\end{tabular}


university graduate was 110 (85.9\%), while only 4 (2.4\%) and $24(14.4 \%)$ of diploma holders were respectively dumped used injections on ground and litters, no significant difference was observed ( $\mathrm{p}=0.19$ ).

The current study revealed that, 15 (28.3\%) of males were used to recap injection after use, while 53 (21.4\%) of the females did the same, significant association was observed ( $\mathrm{p}<0.001)$. The females used to daily administer injections more frequently compared to males 37 (14.9\%), difference was significant $(\mathrm{p}=0.034)$.

The influence of HWs' type of residence on the frequent administration of disposal syringes per day had shown a non significant difference, $(\mathrm{p}=0.77)$. Out of the urban graduated HWs 193 (78.8\%) were administering disposal syringes more than once, while 35 (82.3\%) of the rural did the same. The study revealed that the frequency of daily administered injections in urban areas was more than those in rural ones, no significant difference was observed $(p=0.46)$.

A non significant difference was observed when correlating the impact of residence with the reuse of disposable injections, number of injections given per day and the number of injections' sticks, Table 4.

Regarding influence of hands' wash before and after injection administration and injection recapping after use, the study had revealed significant difference for hand washing $(p=0.014)$ and recapping $(p=0.003)$. Health workers in surgical departments had fully conforming to prevention criteria of hands' washing (100\%). Different departments' status of hands washing during and recapping after injection processes were shown in Table 5.

In the current study, 22 (17.2\%) of the university graduates were vaccinated against Hepatitis B vaccine, while $47(28.7 \%)$ of the diploma holders did the same, difference was not significant ( $p=0.052$ ). Out of the university graduates 99 (77.4\%) had needles' sticks less than five times during working life, while 140 (84.1\%) of diploma holders had the same. No significant difference was observed $(p=0.308)$.

\section{Discussion}

Safe disposal of injection reducing the spreading out of infectious diseases among health workers and patients. In this study, the proportion of the use of safety boxes to dispose syringes after administration was $84 \%$. The use of safety boxes greatly reduces the infection risk within health facilities; although creates large volumes of used needles and syringes that must be safely disposed to prevent infection risk to the community as reported by Sudesh et al. [9]. The current study had shown that $52 \%$ of health workers used to administer more than 10 injections per day that leads to an increased load and may increase the pattern of unsafe injection administration that can be replaced by other methods of treatment such as oral medication. Out of all injections administered in this study; 95\% were given for curative purposes and these in general may to be unnecessary practice as

Table 4. Residence by reuse of disposable injections, number of injections given per day and the number of injections' sticks.

\begin{tabular}{|c|c|c|c|c|c|c|c|c|c|}
\hline \multirow{2}{*}{ Residence } & \multicolumn{3}{|c|}{ Disposal Syringe More Once } & \multicolumn{4}{|c|}{ Number of Injection } & \multicolumn{2}{|c|}{ Stick needle during Work } \\
\hline & Yes & No & Sometime & $1-10$ & $11-20$ & $21-30$ & More 30 & Yes & No \\
\hline Rural & $16.7 \%$ & $82.3 \%$ & $0.1 \%$ & $47.6 \%$ & $31.0 \%$ & $14.3 \%$ & $7.1 \%$ & $81.0 \%$ & $19.0 \%$ \\
\hline Significance & \multicolumn{3}{|c|}{$p=0.77$} & \multicolumn{4}{|c|}{$p=0.46$} & \multicolumn{2}{|c|}{$p=0.34$} \\
\hline
\end{tabular}

Table 5. Departments' injection administration by hand routine washing and recapping.

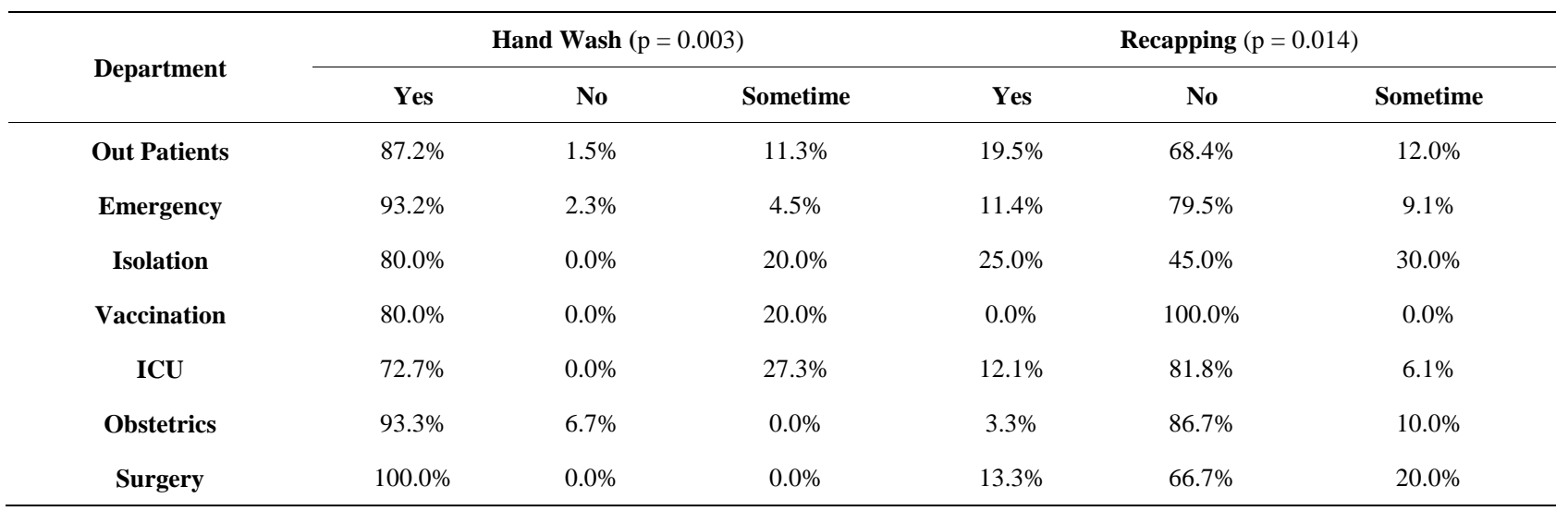


revealed by Simonsen et al. [10]. To improve the safety of injections there must be a major drive by both national authorities and international partners to reduce the total number of injections [11].

The study had shown that, most infectious diseases occur due to unsafe use and disposal of injections that may increase mortality in communities. As revealed by Kalra et al. [12], among many factors; efficacy of injection therapy depends on correct injection technique that to be learned through guidelines, thus in order to reduce the negative impacts of injection administration, authorities should increase awareness of the workers in the hospitals and health centers toward safe use and disposal of injections.

Health care workers, in general are at high risk for needle stick injuries and specially those who are responsible for injection administration or those who in direct use of medical sharps. Reporting of such incidences is a critical for prophylaxis or instant treatment. The obtained high rate of prevalence of needlesticks in this study $74.3 \%$ was in agreement with Makary et al. [13] study that revealed $83 \%$ of surgeons had had a needlestick injury during training. Unfortunately most of these injuries were not reported to employ service and author was attributed this to lack of time. In another German relevant study Wicker et al. [14], had reported, that 31.4\% of participant HCWs had exposed at least to one needlestick injury in the last year and this was varied in the number of reported cases across disciplines. Physicians as reported by the same study had sustained the highest risk to experience needlesticks (55.1\%) this was confirmed by a Manglore [15] study that Doctors were the most frequent victims (64.7\%). In an Iranian study Shiva et al. [16] had reported that $49.3 \%$ of investigated health care workers in five university hospitals had incurred at least once needle stick injury.

The accidental needle stick is one of the factor scausing spreading out of infectious diseases among health care workers; this study showed that $74.3 \%$ of HWS were susceptible to needle stick during their career, thus a prevention guidelines should be adopted. The institution of regulatory measures to curbing the risks of unsafe use and disposal of injections is essential. Needle sticks reporting system and evaluation measures are important in curbing infections resulted from a mal use and unsafe disposal. Most of the providers in the current study $92.0 \%$ had shown a satisfactory response towards the adopted evaluation measures of prevention of after use injections' hazards. Standardized procedure is better be used to assess all reported occupational exposures to blood [17].

The present study revealed a routine after use recapping pattern of injection (26\%) which might lead to possibility of needle's stick as reported by Khushdil et al. [18] that (55\%) of nurses got needle sticks and 58\% of them were injured at the time of recapping the syringe. The needle recapping in current study was less when compared with a Nigerian study [19] that $30.4 \%$ of health workers recap needles. Mahfouz [20] and Hutin [21] reported that needle recapping with other factors are the major causes of injury among health workers.

In a British study, senior surgeons reported 29 needle stick injuries in two years [22] while 59\% of 311 German medical students recalled at least one needle stick injury during their medical study [24].

Hepatitis B is the one of the most infectious diseases that transmitted through accidental sticks of used injections among providers; thus vaccination is a vital preventive measure to curbing the spreading out of cross infection. The current study had shown a satisfactory rate of vaccination $76.4 \%$ against Hepatitis B Viral infection (HBVi) among HCWs in Saudi Arabia. Omer et al. [23] assured that vaccination is one of the most available effective prevention measures to clinicians and the success of immunization programs depends the rates HCWs acceptance and to the extent of coverage.

In this study, $79.3 \%$ of responded HCWs had education courses on safe injections that can improve dealing with the use and disposal of administered injections. Improved access to medical care and drug treatment has been attributed to attendance at safer injecting facilities as reported by Wyatt [24]. The use of disinfectants to sterilize the site of administration of injections helps to prevent spreading out of microbes, this curbing infection measure was fully adopted in KSA, since $95 \%$ of respondents were using sterile disinfectants before injection administration.

Out of the used injections in the investigated health settings, only (32.8\%) were incinerated inside the health settings where the administration was taking place, while the rest were disposed outside them. A waste management solution that has proven to be both practical and effective in many countries for both routine immunization services and mass campaigns is the incineration of used needles and syringes on a district basis [25].

The useful observation of utilized standard operating procedures (SOPs) among providers in Saudia86.4\% may highly affect the performance of health workers in injections' administration techniques. Furthermore, this can be supported by continuing medical education programs. Periodic monitoring and such interventions may also further improve safe injection practices [22].

\section{Conclusion}

Proper use and disposal of injection are the main curbing measures for infection prevention during use of injection and sharp medical devices. Needlestick injuries are the major concern in spreading out of infectious diseases. 
Continued education in safe use and disposal of injection, along with institution of guidelines, mandatory reporting of needle sticks and staff vaccination is recommended.

\section{Acknowledgements}

Author would like to acknowledge the sincere assisstance that was offered by Dr. Mustafa AwadElkarim Abd Alla in data processing and the pharmacists: Bader Al Thobaity, Motlak Al Joaid and Bader Al Asmary for data collection.

\section{REFERENCES}

[1] S. Gyawali, D. S. Rathore, P. R. Shankar and K. C. Vikash Kumar, "Strategies and Challenges for Safe Injection Practice in Developing Countries," Journal of Pharmacology and Pharmacotherapeutics, Vol. 4, No. 1, 2013, pp. 8-12.

[2] Y. J. Hutin, A. M. Hauri and G. L. Armstrong, "Use of Injections in Health Care Settings Worldwide, 2000: Literature Review and Regional Estimates,” BMJ, Vol. 327, No. 7423, 2003, pp. 1075-1078. http://dx.doi.org/10.1136/bmj.327.7423.1075

[3] E. Drucker, P. G. Alcabes and P. A. Marx, “The Injection Century: Massive Unsterile Injections and the Emergence of Human Pathogens,” Lancet, Vol. 358, No. 9297, 2001, pp. 1989-1992. http://dx.doi.org/10.1016/S0140-6736(01)06967-7

[4] M. Kermode, W. Holmes, B. Langkham, M. S. Thomas and S. Gifford, "Safer Injections, Fewer Infections: Injection Safety in Rural North India,” Tropical Medicine \& International Health, Vol. 10, No. 5, 2005, pp. 423-432. http://dx.doi.org/10.1111/j.1365-3156.2005.01421.x

[5] Geneva: World Health Organization (WHO), "Safety of Injections Question and Answers," Publication No. WHO/EHT/04.06, Secretariat of the Safe Injection Global Network, Department of Essential Health Technologies, 2011.

http://who.int/injection_safety/resources/en/index.html

[6] H. Riaz, S. W. Kamal, T. Riaz, S. Aziz, J. Rajper and W. Noorulain, "Methods of Disposal of Used Syringes by Hepatitis B and C Patients at an Urban and Rural Setting," Journal of Pakistan Medical Association, Vol. 62, No. 1, 2012, pp. 81-84. http://jpma.org.pk/full_article_text.php?article_id=3241

[7] A. Kane, J. Lloyd, M. Zaffran, L. Simonsen, M. Kans, et al., "Transmission of Hepatitis B, Hep C and HIV through Unsafe Injections in the Developing World; Model Based Regional Estimates,” Bull World Health Organ, Vol. 77, No. 10, 1999, pp. 801-807.

[8] WHO, The World Health Report 2002. Reducing Risks, Promoting Healthy Life 2002. http://www.who.int/whr/2002/en

[9] B. S. Hersh, R. M. Carr, J. Fitzner, et al., "Ensuring Injection Safety during Measles Immunization Campaigns: More than Auto-Disable Syringes and Safety Boxes," The Journal of Infectious Diseases, Vol. 187, No. Suppl 1,
2003, pp. S299-S306.

[10] L. Simonsen, A. Kane, J. Lloyd, M. Zaffran and M. Kane, "Unsafe Injections in the Developing World and Transmission of Bloodborne Pathogens: A Review,” Bull World Health Organ, Vol. 77, No. 10, 1999, pp. 789-800.

[11] A. Battersby, R. Feilden, P. Stoeckel, A. Da Silva, C. Nelson and A. Bass, "Strategies for Safe Injections," Bull World Health Organ, Vol. 7, No. 12, 1999, pp. 996-1000.

[12] S. Kalra, Y. P. S. Balhara, M. P Baruah, M. Chadha, H. B. Chandalia, S. Chowdhury, K. M. P. Kumar, S. Modi, S. Pitale, R. Shukla, R. Sahay, A. Sundaram, A. G. Unnikrishnan and S. K. Wangnoo, "Forum for Injection Techniques, India: The First Indian Recommendations for Best Practices in Insulin Injection Technique,” Indian Journal of Endocrinology and Metabolism, Vol. 16, No. 6, 2012, pp. 876-885.

[13] M. A. Makary, A. Al-Attar, C. G. Holzmueller, J. B. Sexton, D. Syin, M. M. Gilson, M. S. Sulkowski and P. J. Pronovost, "Needlestick Injuries among Surgeons in Training," The New England Journal of Medicine, Vol. 356, No. 26, 2007, pp. 2693-2699.

http://dx.doi.org/10.1056/NEJMoa070378

[14] S. Wicker, F. Nürnberger, J. B. Schulze and H. F. Rabenau, "Needlestick Injuries among German Medical Students: Time to Take a Different Approach?” Medical Education, Vol. 42, No. 7, 2008, pp. 742-745. http://dx.doi.org/10.1111/j.1365-2923.2008.03119.x

[15] K. P. Prakash, "Epidemiology of Needle-Stick Injuries in Mangalore,” Journal of Evolution of Medical and Dental Sciences, Vol. 1, No. 3, 2012, p. 128.

[16] F. Shiva, A. Sanaei, A. R. Shamshiri and F. Ghotbi, "Survey of Needle-Stick Injuries in Paediatric Health,” Journal Pakistan Medical Association, Vol. 61, No. 2, 2011, pp. 127-131.

[17] E. Drucker, P. Lurie, A. Wodak and P. Alcabes, "Measuring Harm Reduction: The Effects of Needle and Syringe Exchange Programs and Methadone Maintenance on the Ecology of HIV,” AIDS, Vol. 12, No. Suppl A, 1998, pp. S217-S230.

[18] A. Khushdil, H. Farrukh, M. D. Sabir, T. Awan and T. Qureshi, "Needle Stick Injuries in Nursesat A Tertiary Health Care Facility," Journal of Postgraduate Medical Institute, Vol. 27, No. 4, 2013, pp. 381-386.

[19] A. Onyemocho1, J. I. Anekoson and E. O. Pius, "Knowledge and Practice of Injection Safety among Workers of Nigerian Prison Service Health Facilities in Kaduna State," American Journal of Public Health Research, Vol. 1, No. 7, 2013, pp. 171-176. http://dx.doi.org/10.12691/ajphr-1-7-5

[20] A. A.-R. Mahfouz, I. Abdelmoneim, M. Y. Khan, A. A. Daffalla, M. M. Diab. H. Shaban and H. S. Al Amri, "Injection Safety at Primary Health Care Level in SouthWestern Saudi Arabia,” Eastern Mediterranean Health, Vol. 15, No. 2, 2009, pp. 443-450.

[21] Y. Hutin, A. Hauri, L. Chiarello, M. Catlin, B. Stilwell, T. Ghebrehiwet and J. Garner, "Best Infection Control Practices for Intradermal, Subcutaneous, and Intramuscular Needle Injections,” Bull World Health Organ, Vol. 81, No. 7, 2003, pp. 491-500. 
[22] D. E. Koziol and D. K. Henderson, "Risk Analysis and Occupational Exposure to HIV and HBV," Current Opinion in Infectious Diseases, Vol. 6, No. 4, 1993, pp. 506510.

http://dx.doi.org/10.1097/00001432-199308000-00003

[23] S. B. Omer, D. A. Salmon, W. A. Orenstein, M. P. de Hart and N. Halsey, "Vaccine Refusal, Mandatory Immunization, and the Risks of Vaccine-Preventable Diseases," The New England Journal of Medicine, Vol. 360, No. 19, 2009, pp. 1981-1988.
[24] H. V. Wyatt, "The Popularity of Injections in the Third World: Origins and Consequences for Poliomyelitis,” Social Science \& Medicine, Vol. 19, No. 9, 1984, pp. 911915. http://dx.doi.org/10.1016/0277-9536(84)90320-4

[25] F. P. Mitrano, R. J. Baptista, D. W. Newton and S. C. Augustine, "Microbial Contamination Potential of Solutions in Prefilled Disposable Syringes Used with a Syringe Pump," American Journal of Hospital Pharmacy, Vol. 43, No. 1, 1986, pp. 78-80. 